\title{
Solvents interactions with thermochromic print
}

\section{ABSTRACT}

In this study, the interactions between different solvents (benzene, acetone, cyclohexanone, various alcohols and water) and thermochromic printing ink were investigated. Thermochromic printing ink was printed on metal surface. Components of thermochromic printing inks are polymeric microcapsules and classic yellow offset printing ink. Below its activation temperature, dye and developer within the microcapsules form a blue coloured complex. Therefore, thermochromic print is green. By heating above the activation temperature, blue colour of the complex turns into the leuco dye colourless state and the green colour of the prints turns into the yellow colour of the classic offset pigment. The results of the interaction with various solvents show that the thermochromic print is stable in all tested solvents except in ethanol, acetone and cyclohexanone. In ethanol, the green colour of the print becomes yellow. SEM analysis shows that microcapsules are dissolved. In acetone and cyclohexanone, the green colour of the print turns into blue, and the microcapsules become significantly more visible. Thus, the yellow pigment interacts with examined ketones. Based on the obtained interactions it can be concluded that the microcapsules have more polar nature than the classical pigment particles. Solvent-thermocromic print interactions were analysed using Hansen solubility parameters that rank the solvents based on their estimated interaction capabilities.

\author{
Mirela Rožić, \\ Marina Vukoje, \\ Dominik Kapović, \\ Livia Marošević \\ University of Zagreb, Faculty of \\ Graphic Arts, Zagreb, Croatia \\ Corresponding author: \\ Marina Vukoje \\ e-mail: marina.vukoje@grf.hr
}

First recieved: 14.07.2017

Accepted: 04.09.2017.

\section{KEY WORDS}

thermochromic ink, solvent, microcapsules, interactions

\section{Introduction}

The thermochromic ink composition includes a thermochromic microcapsules and an ink vehicle. Thermochromic microcapsules usually consist of at least three components - the colorant, colour developer and solvent. In order to achieve desired effect, the components are mixed in precisely determined proportions and encapsulated in a polymer envelope in order to protect him against external influences (Kulčar et al., 2010).

The thermochromic effect in thermochromic leuco dye-developer-solvent systems is caused by the formation of leuco dye-developer complex. Formation between the colorant (leuco dye) and developer predominates on lower temperatures. Organic solvent at lower temperatures is in solid state, and with the increase of temperature it becomes liquid. The solvent in liquid state causes destruction of the colorant - developer complex resulting in separation of both components. When the thermochromic complex cools again, the solvent becomes solid, and the developer and colorant blend again and the colour returns to its original state (Kulčar et al., 2010; Aitken et al., 1996). The solvent component of reversible thermochromic systems determines the switching temperature of the colour change. Paraffin, long chain alcohols, alkyl amides and alcanoic acids are solvents typically 
used. Most solvents contain a long hydrocarbon chain (Kulčar et al., 2010; Bamfield, 2010; Seeboth et al., 2007; Christie \& Bryant, 2005; Lee et al., 2007).

Colour developers are weak organic acids which act as proton donors. The phenols - bisphenol A (BPA), laurylgallate (LG), ethylgallate (EG) and p-hydroxybenzoic acid methyl ester - are typical developers for reversible thermochromic leuco dye-developer-solvent systems (Seeboth et al., 2007).

Encapsulation with melamine resin is a common method widely described in the literature. Only a few examples of encapsulation with epoxy resin have been reported (Seeboth et al., 2007; Bamfield, 2010). Melamine resin or melamine formaldehyde (also shortened to melamine) is a thermosetting plastic material made from melamine and formaldehyde by polymerization (Figures 1 and 2). Melamine resin capsules have a core-shell geometry. Melamine formaldehyde is very hard and will not break down at high temperature (Bamfield, 2010). Epoxy resins possess better temperature stability in comparison to melamine resins. The term "epoxy", "epoxy resin", refers to a broad group of compounds that are characterized by the presence of an oxirane or epoxy ring shown in Figure 3. This is represented by a three-member ring containing an oxygen atom that is bonded with two carbon atoms already united in some other way (Thompson, 2004). Despite the rapid development of instrumental analytical methods, classic analytical approaches still have their place. Solvent precipitation techniques are often used in the first stages of ink analysis to affect separation of an ink into its major component. With regards to the type of printing ink, it is often necessary to choose a solvent that will interact with the individual components of ink. The resulting fractions can be examined using some appropriate identification techniques (Leach \& Pierce, 1999).<smiles>CCNc1nc(NC(C)C)nc(NC(C)C)n1</smiles>

» Figure 1: Structure of melamine resins

In this study, preliminary studies of interactions between thermochromic printing ink and various solvents have been carried out. The data obtained can be used to determine the ink extraction scheme.

\section{Experimental}

One leuco dye based thermochromic offset printing ink was used (Chromatic Technologies, Inc.). The activation temperature of thermochromic ink is $45^{\circ} \mathrm{C}$. Below its activation temperature, the print was coloured in green and above its activation temperature the print was coloured in yellow. Used ink was oil-based containing leuco dye system as colorant. In preparation of the experiment metal plate were used as printing substrate. The printing trials were carried out using

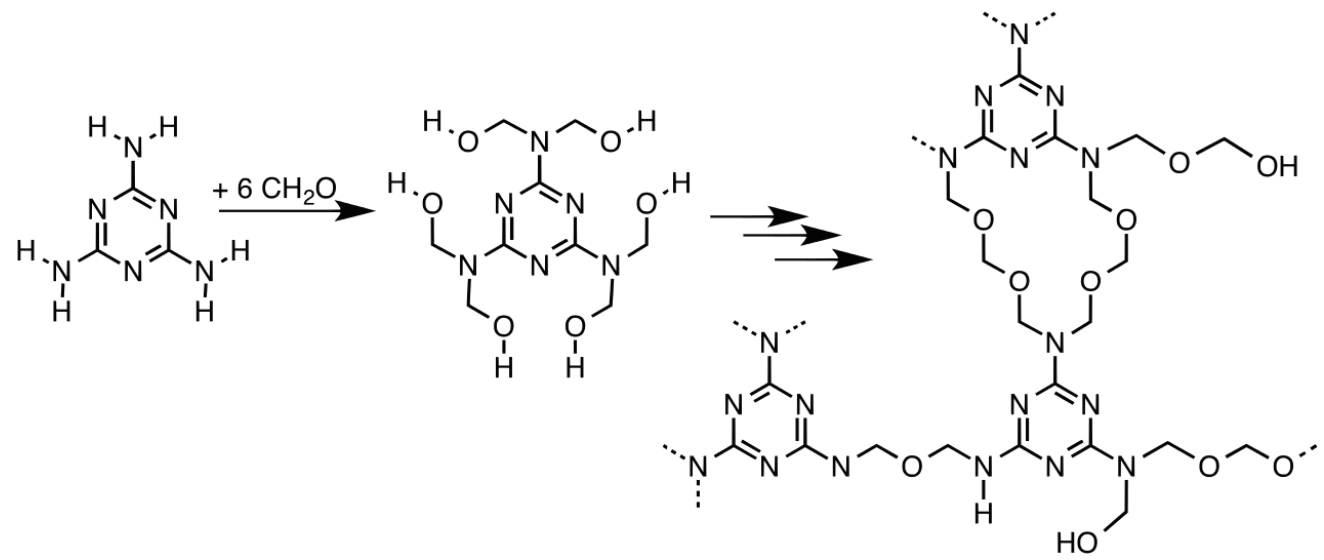

» Figure 2: Chemical reactions leading to melamine-formaldehyde resin<smiles>CC(C)(CC(O)COc1ccc(C(C)(C)c2ccc(OCC3CO3)cc2)cc1)CC1CO1</smiles>

» Figure 3: Epoxy resin structure 
Prüfbau Multipurpose Printability Tester. The quantity of $1.5 \mathrm{~cm}^{3}$ ink was applied on the distribution rollers while printing was carried out with the printing force of $600 \mathrm{~N}$. All the samples were printed in the full tone.

After printing, the metal plate was cut into several smaller tiles of $1 \times 1 \mathrm{~cm}$. Plates were immersed in glasses containing $20 \mathrm{~cm}^{3}$ of solvent. The following solvents were used: acetone, cyclohexanone, ethanol, benzene, cyclohexanol, butanol, pentanol, hexanol, isobutanol, propan-2-ol, ethylene glycol and water. Samples were soaked in solvents for 2 days.

When the samples were dried, the colour measurements were carried out using Konica Minolta spectrophotometer at temperatures of 23 and $50 \pm 2{ }^{\circ} \mathrm{C}$ (below and above its activation temperature). After heating at $50^{\circ} \mathrm{C}$, the samples were cooled again at $23^{\circ} \mathrm{C}$ in order to examine the preservation of the colour reversibility.

Each print sample was heated by the Full Cover water block (EK Water Blocks, EKWB; Slovenia). The temperature of the copper plate surface was varied by circulation of thermostatically controlled water in channels inside the water block, which was assured to be up to $1^{\circ} \mathrm{C}$ accurate in the applied temperature region. The colour of prints was determined according to the CIE L*a*b* system.
The thermocromic surfaces were monitored using a FE-SEM Jeol 7000 field emission scanning electron microscope too.

\section{Results and discussion}

Photos of samples were taken in order to visually evaluate the prints. Figure 4 shows visual evaluation. Thermochromic prints are stabile in all solvents besides acetone, cyclohexanone and ethanol (Figure 4a). The colour of the print turned from green into yellow after interaction with ethanol. After interaction with acetone and cyclohexanone the colour of the print was changed to blue.

SEM micrograph (Figure 5) shows that microcapsules in thermochromic ink after printing stay more or less covered by the binder.

After interaction with acetone the microcapsules become more visible (Figure 6). Since the colour of the print was changed to blue, it can be assumed that a yellow pigment (or yellow offset ink) was dissolved in acetone.

After interaction with cyclohexanone microcapsules become more visible (Figure 7). The diameter of the microcapsules ranges from 1 to $3 \mu \mathrm{m}$.

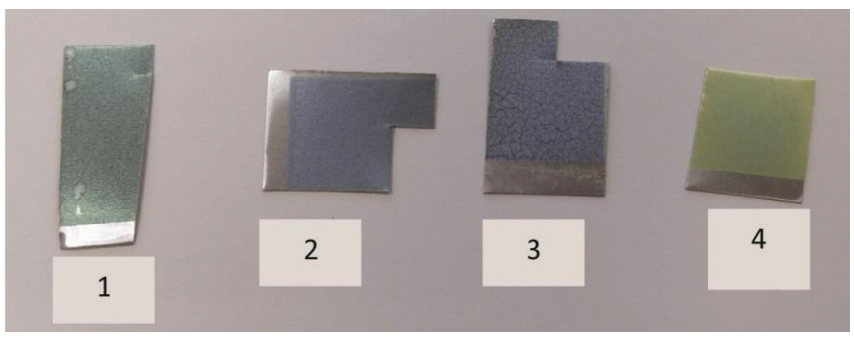

» Figure 4a: Thermochromic prints: 1-orginal sample and after interaction with 2-acetone, 3-cyclohexanone, 4-ethanol

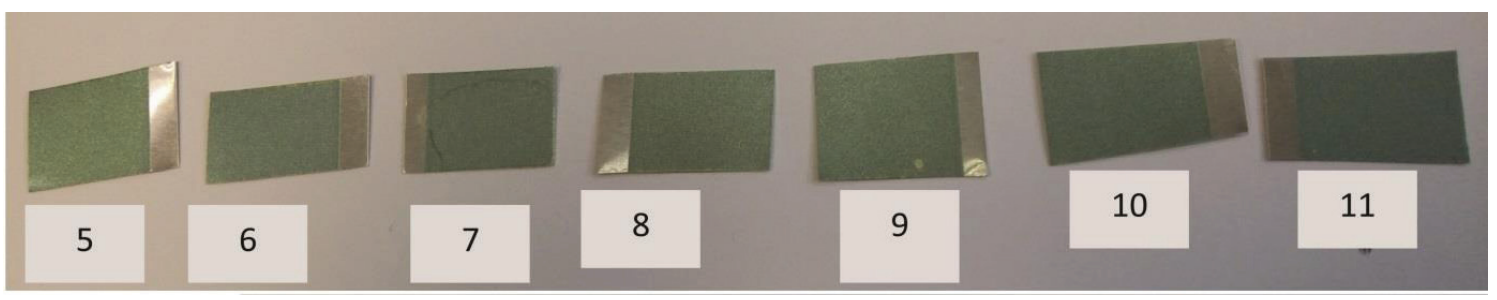

» Figure 4b: Thermochromic print after interaction with: 5-benzene, 6-cyclohexanol, 7-butanol, 8-pentanol, 9-hexanol, 10-isobutanol, 11-propan-2-ol

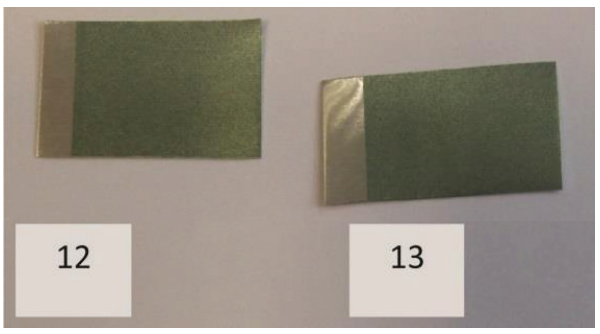

» Figure 4c: Thermochromic print after interaction with: 12-ethylene glycol, 13-distilled water 


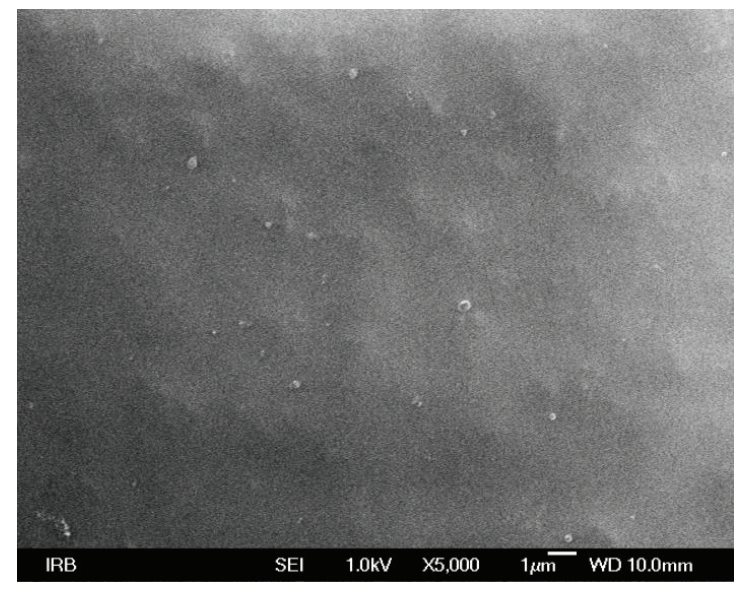

» Figure 5: SEM micrograph of original green thermochromic print (magnification 5000x)

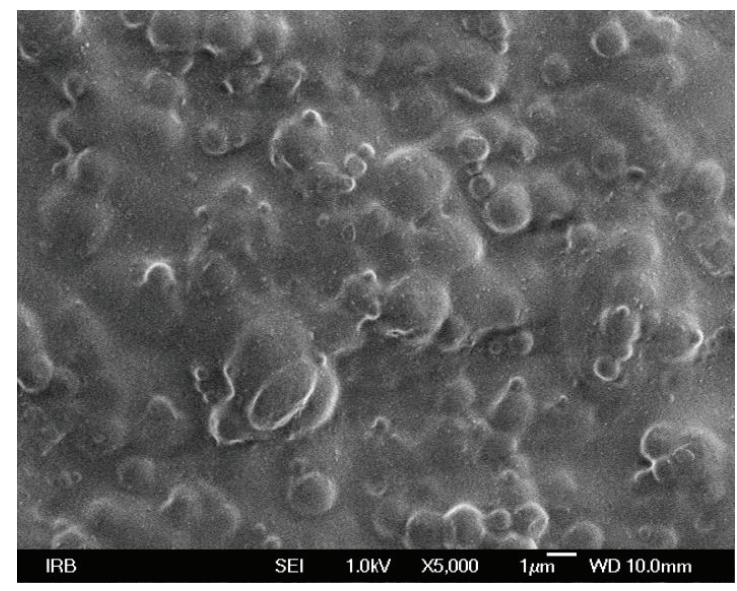

» Figure 7: SEM micrograph of green thermochromic print after interaction with cyclohexanone (magnification 5000x)

After interaction with ethanol, cracks with a diameter of about $1 \mu \mathrm{m}$ are formed, so it can be assumed that microcapsules have dissolved in those places (Figure 8).

When a colour is expressed in CIELAB, $a^{*}$ denotes the red/green value. A colour measurement movement in the-a direction depicts a shift toward green. After interaction with solvents, the prints retained the reversibility of the colour change (Figure 9). At the initial temperature of $23^{\circ} \mathrm{C}$ all prints except the prints interacting with acetone, cyclohexanone and ethanol have approximately the same $a^{*}$ values. Print samples which have interacted with acetone, cyclohexanone and ethanol have more positive $a^{*}$ values, while the greatest change in $a^{*}$ value was obtained after interaction with cyclohexanone.

Along the $b^{*}$ axis,- $b$ movement represents a shift toward blue, and $+b$ toward yellow. $b^{*}$ values at the initial temperature of $23^{\circ} \mathrm{C}$ are practically the same

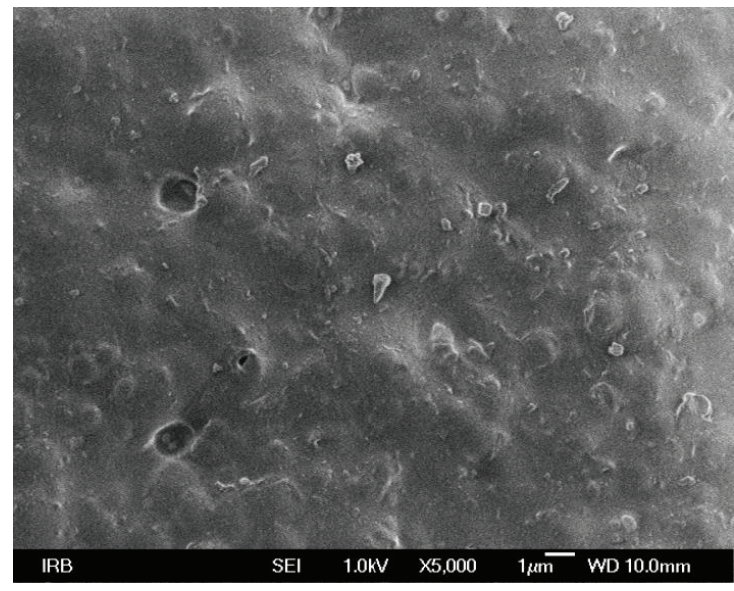

» Figure 6: SEM micrograph of green thermochromic print after interaction with acetone (magnification 5000x)

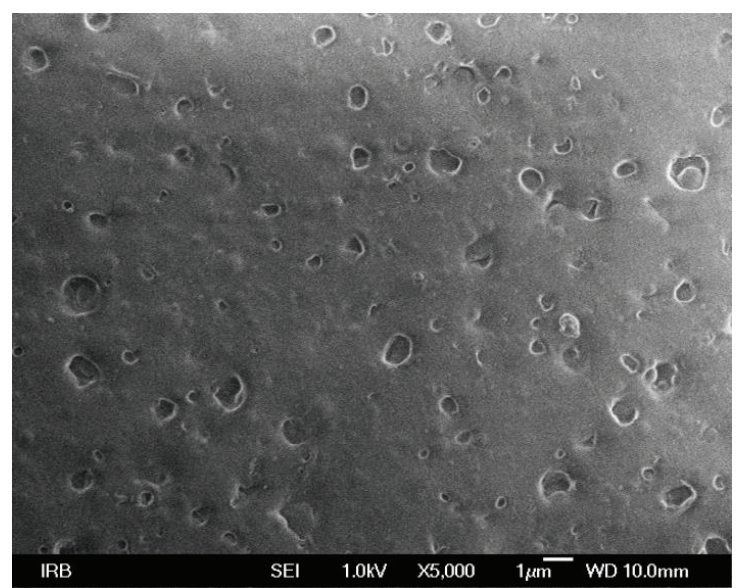

» Figure 8: SEM micrograph of green thermochromic print after interaction with ethanol (magnification 5000x)

for all samples except for samples interacting with acetone, cyclohexanone and ethanol (Figure 10).

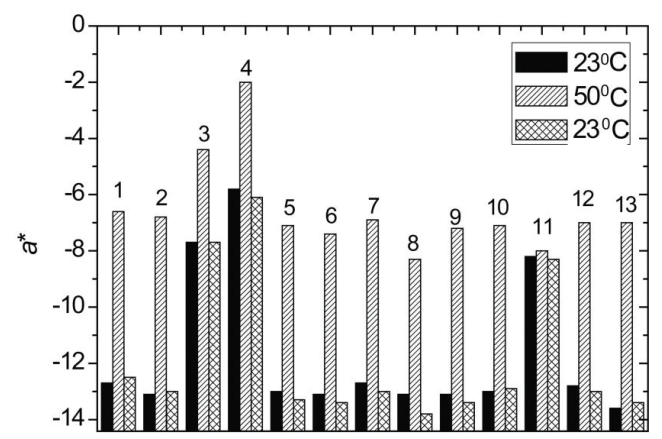

» Figure 9: $a^{*}$ values of the prints at temperatures 23, 50 and repeated cooling to $23{ }^{\circ} \mathrm{C}$ (1-orginal and after interaction with: 2- benzene, 3-acetone, 4-cyclohexanone, 5-propan-2-ol, 6-isobutanol, , 8-pentanol, 9-hexanol, 10-cyclohexanol, 11-ethanol, 12-ethylene glycol, 13-water) 


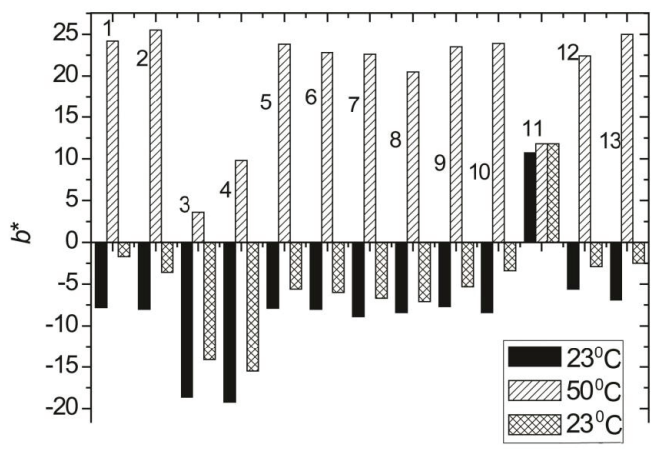

" Figure 10: $b^{*}$ values of the prints at temperatures 23 , 50 and repeated cooling to $23{ }^{\circ} \mathrm{C}$ (1-orginal and after interaction with: 2- benzene, 3-acetone, 4-cyclohexanone, 5-propan-2-ol, 6-isobutanol, , 8-pentanol, 9-hexanol, 10-cyclohexanol, 11-ethanol, 12-ethylene glycol, 13-water)

The samples interacting with acetone and cyclohexanone have more negative $b^{*}$ value (greater shift to blue area), while the sample interacting with ethanol has a positive $b^{*}$ value (greater shift to yellow area). After the interaction with acetone, the $b^{*}$ value is slightly more positive compared to interaction with cyclohexanone. A greater shift to the blue area was obtained after interaction with the cyclohexanone. This was also confirmed with SEM micrographs (Figures 6 and 7).

By heating to $50{ }^{\circ} \mathrm{C}, \mathrm{b}^{*}$ values become positive (shift to yellow area). The prints which were in contact with acetone and cyclohexanone also change their colour in yellow, but the shift to the yellow area was smaller compared to those obtained for samples interacting with other solvents (Figures 10 and 11). This arises from partial but not completely dissolution of yellow pigment in acetone and cyclohexanone.

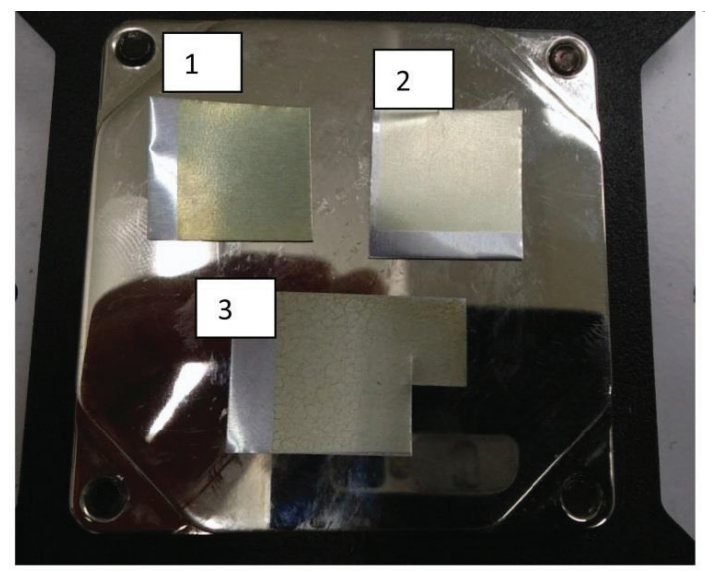

» Figure 11: The samples of thermochromic prints after interaction with 1) ethanol, 2) acetone and 3) cyclohexanone at $50^{\circ} \mathrm{C}$

The print which was in interaction with ethanol at $50{ }^{\circ} \mathrm{C}$ becomes yellow. With repeated cooling at $23^{\circ} \mathrm{C}$, the $b^{*}$ value of the prints (except for the print soaked in ethanol) were much more positive compared to those obtained at the initial temperature which was also $23^{\circ} \mathrm{C}$ (Figure 10). It is possible that the microcapsules by heating change their shape, i.e. they spread and need to be cooled.

Varied classification systems were developed to rank the solvents based on their estimated interaction capabilities. Solvatochromic scale base on the solvent properties. The Reichardt's scale, the Snyder scale, Hildebrand and Hansen scale, Abraham scale, COSMO-RS approach are included in solvatochromic scale base (Lesellier, 2015; Hansen, 2000).

Snyder suggested three parameters, $x_{e^{\prime}} x_{d}$ and $x_{n}$ respectively describing hydrogen bond basicity, hydrogen bond acidity and the solvent dipolarity. This scale is a polarity scale and does not include the dispersive interactions. The sum of the parameters $\left(x_{i}\right)$ is equal to 1 (Lesellier, 2015).

Hansen solubility parameters (HSP) were developed by Charles M. Hansen as a way of predicting if one material will dissolve in another and form a solution. They are based on the idea that "like dissolves like" where one molecule is defined as being 'like' another if it bonds to itself in a similar way. Hansen suggested that the solubility parameter was the sum of dispersive $\left(\delta_{d}\right)$, polar $\left(\delta_{p}\right)$ and hydrogen bonding $\left(\delta_{h}\right)$ (donor and acceptor). Compared to the Snyder scale, Hansen scale includes dispersive interactions, and joined the hydrogen bond acidity and basicity. Hansen solubility parameters can be treated as vector for a point in three dimensions also known as the Hansen space. The nearer two molecules are in this three dimensional space, the more likely they are to dissolve into each other (Hansen, 2000).

\section{Table 1}

Hansen solubility parameters (HSP)

(Lesellier, 2015; Hansen, 2000)

\begin{tabular}{l|c|c|c}
\hline \multicolumn{1}{c|}{ Solvent } & $\boldsymbol{\delta}_{\mathrm{d}}$ & $\boldsymbol{\delta}_{\mathrm{p}}$ & $\boldsymbol{\delta}_{\mathrm{h}}$ \\
\hline Benzene & 18.4 & 0 & 2.00 \\
\hline Cyclohexanone & 17.8 & 8.4 & 5.08 \\
\hline Acetone & 15.5 & 5.3 & 11.7 \\
\hline Propan-2-ol & 15.8 & 6.1 & 16.4 \\
\hline Isobutanol & 15.1 & 5.7 & 16 \\
\hline Cyclohexanol & 17.4 & 4.1 & 13.5 \\
\hline Hexanol & 15.9 & 5.8 & 12.5 \\
\hline Pentanol & 15.9 & 5.9 & 13.8 \\
\hline Butanol & 16.0 & 5.7 & 15.8 \\
\hline Ethanol & 15.8 & 8.8 & 19.4 \\
\hline Ethylene glycol & 17 & 11 & 26 \\
\hline Water & 15.6 & 16.0 & 42.3 \\
\hline
\end{tabular}


Table 1 shows Hansen solubility parameters of tested solvents, while Figure 12 presents the relationship between hydrogen and polar interactions of tested solvents. Benzene interacts with dispersion interactions. Other tested solvents interact with hydrogen and polar interactions. In cyclohexanone, the polar interactions are stronger than hydrogen bonding while other solvents have higher share of hydrogen bond interactions. Cyclohexanone interacts in a larger proportion with dispersion interactions. It can be concluded that the yellow pigment, since it is soluble in cyclohexanone, is not non-polar but it contains functional groups which interact with polar interactions but the proportion of dispersion interactions is higher which can be attributed to the structure of the coloured organic compounds. The proportion of hydrogen bonded interactions is small (Figure 12). Acetone interacts with stronger hydrogen bonds, but weaker dispersion forces and polarity than cyclohexanone, and therefore the yellow pigment is less soluble in it.

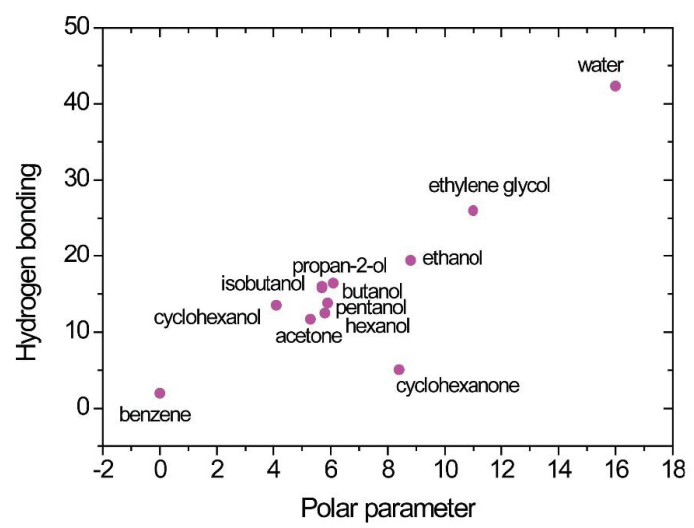

» Figure 12: Relation between hydrogen bonding and
polar parameters of tested solvents

Alcohols interact by hydrogen and dispersion interactions. Alcohols with larger molecular weight (cyclohexanol, hexanol, pentanol) are coupled with stronger dispersion interactions and weaker hydrogen interactions. The lower molecular weight alcohols (propan-2ol, isobutanol and ethanol) are coupled with stronger hydrogen bonds and weaker dispersion interactions. Due to the lowest molecular weight, ethanol interacts with the strongest hydrogen interactions and relatively weak dispersion interactions. Polar alcohol interactions are small except for ethanol whose molecules are associated with stronger polar interactions. Compared to the cyclohexanone, dispersion interactions of alcohols are weaker and the hydrogen interactions are stronger. Polar interactions are considerably lower compared to dispersion and hydrogen interactions. Due to dissolution of microcapsules in ethanol, the surface of the microcapsules is certainly more polar than the surface of the yellow pigment or it contains more polar functional groups. Ethylene glycol and especially water molecules are coupled to the highest degree by hydro- gen bonds and in a lower degree by dispersion interactions, so they do not interact with the microcapsules.

\section{Conclusions}

Microcapsules of the tested thermochromic printing ink contain polar functional groups which interact with hydrogen bonding. Therefore, it could be assumed they are made from melamine resin (Figures 1 and 2). They dissolve in ethanol, but not in the other examined alcohols, due to stronger polar and hydrogen bonds interactions of ethanol. Because it's a polymer, dispersion interactions are also important. Yellow pigment interacts primarily through dispersion interactions and in a lower degree by polar interactions. Therefore it dissolves in cyclohexanone. The obtained results can be used for characterization of thermochromic inks and determination of the solvents sequence used in sequential analysis. They also indicate which solvents should not be used in the formulation of thermochromic inks.

\section{References}

Aitken, D., Burkinshaw, S.M., Griffiths, J., Towns, A.D. (1996) Textile applications of thermochromic systems. Review of Progress on Coloration. 26 (1), 1-8. Available from: doi: 10.1111/j.14784408.1996.tb00105.x [Accessed 5th June 2017]. Bamfield, P. (2010) Chromic Phenomena. Cambridge, Royal Society of Chemistry. Available from: doi: 10.1039/9781849731034. [Accessed 6th June 2017].

Christie, R.M. \& Bryant, I.D. (2005) An evaluation of thermochromic prints based on microencapsulated liquid crystals using variable temperature colour measurement. Coloration Technology. 121(4), 187-192. Available from: doi: 10.1111/j.14784408.2005.tb00271.x [Accessed 15th June 2017]. Hansen, C.M. (2000) Hansen Solubility Parameters - A User's Handbook. 2nd edition. Boca Raton, FL, CRC Press, Taylor \& Francis Group. Available from: https://www.google.rs/url?sa=t\&rct=$j \& q=\& e s r c=s \&$ source $=$ web \& $c d=1 \&$ ved $=0 a-$ hUKEwit4P3C8YfYAhWOaVAKHezIAggOFggwMAA\&url=https\%3A\%2F\%2Fwww.researchgate. net\%2Ffile.PostFileLoader.html\%3Fid\%3D54e77596d685ccc40a8b45a1\%26assetKey\%3DAS\%253A273708 806017053\%25401442268672663\&usg=AOvVaw0oJaM38apP4SC2KikTLuEq [Accessed 15th June 2017].

Kulčar, R., Friskovec, M., Hauptman, N., Vesel, A., Gunde, M. K. (2010) Colorimetric properties of reversible thermochromic printing inks. Dyes and Pigments. 86 (3), 271-277. Available from: doi: 10.1016/j. dyepig.2010.01.014. [Accessed 20th June 2017].

Leach, R.H., Pierce, R. J. (eds.) (1999) The Printing Ink Manual. 5th edition. Dordrecht, The Netherlands, Springer. 
Lee, S.C., Jeong, Y.G., Jang, S.H. \& Jo, W.H. (2007) Effect of Alkyl Chain Length on Thermochromism of Novel Nitro Compounds. Fibers and Polymers. 8 (2), 234-236. Available from: doi: 10.1007/ BF02875798 [Accessed 29th June 2017].

Lesellier, E. (2015) Epider diagram: A universal and versatile approach for system comparison and classification: Application to solvent properties. Journal of Chromatography $A$. 1389, 49-64. Available from: doi: 10.1016/j. chroma.2015.02.017. [Accessed 3th July 2017].

Seeboth, A., Klukowska, A., Ruhmann, R. \& Lötzsch, D. (2007) Thermochromic Polymer Materials. Chinese Journal of Polymer Science. 25 (2), 123-135. Available from: doi: 10.1142/ S0256767907001923. [Accessed 9th July 2017].

Thompson, B. (2004) Printing Materials, Science and Technology. UK, Pira International Press.

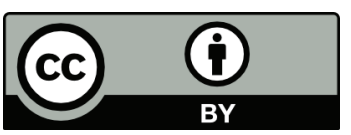

(C) 2017 Authors. Published by the University of Novi Sad, Faculty of Technical Sciences, Department of Graphic Engineering and Design. This article is an open access article distributed under the terms and conditions of the Creative Commons Attribution license 3.0 Serbia (http://creativecommons.org/licenses/by/3.0/rs/). 